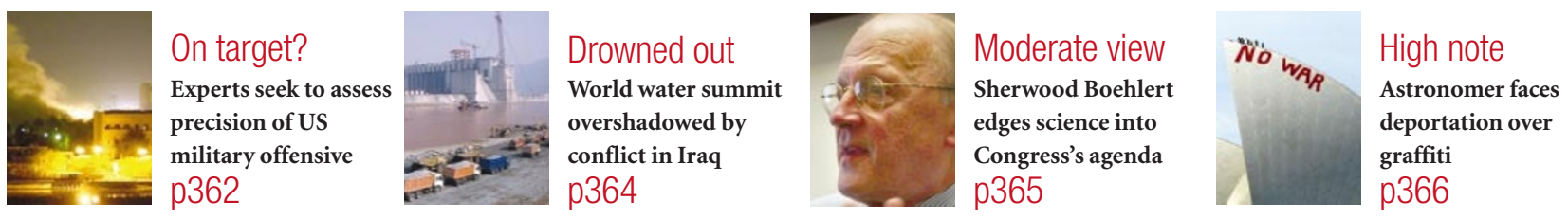

\title{
Academics fume as university refuses to reject tobacco dollars
}

Rex Dalton, San Diego

Academics at the University of California are on a collision course with their administrators this week over a proposal to close the door on the acceptance of research funds from tobacco corporations.

Faculty groups at two of the university system's research campuses have voted for such a ban - partly so they can obtain grants from anti-tobacco funding agencies that only donate to institutions with such a rule in place.

But the votes, at the San Francisco (UCSF) and San Diego (UCSD) campuses, are being resisted by university administrators, who do not want to set a precedent for refusing support from other funding sources, such as pharmaceutical companies.

The bans would infringe academic freedom, argued UCSF anaesthesiologist Jeanine Wiener-Kronish in UCSF Today last month. "There is a danger when limits on research funding are proposed," she says, "as various groups have political agendas."

In a January vote on UCSF's health-science campus, however, researchers voted $52 \%$ to $48 \%$ in favour of a ban, with about one-third of the 1,800 eligible faculty voting. Stan Glantz, a UCSF cardiovascular researcher and ban supporter, says: "It is not appropriate to take money from an industry that kills 5 million people worldwide and constantly lies."

Lawrence Coleman, a physicist and viceprovost for research at the University of California, says he is concerned that accepting grants from agencies that make restrictive stipulations could infringe academic freedom.

The issue has been brought to a head by the American Legacy Foundation - a non-profit organization set up in Washington DC as part of a multi-billion-dollar settlement in 1998 between US state governments and the tobacco industry, to fund tobacco research and education. The foundation donates about $\$ 25$ million a year to researchers, but only to institutions that expresslyban tobacco money. This policy, it says, is a response to the tobacco companies' record of manipulating research findings and inaccurately claiming credit for them.

About 15 US universities have debated the Legacy Foundation's funding restrictions so far, foundation officials say. Ten of them

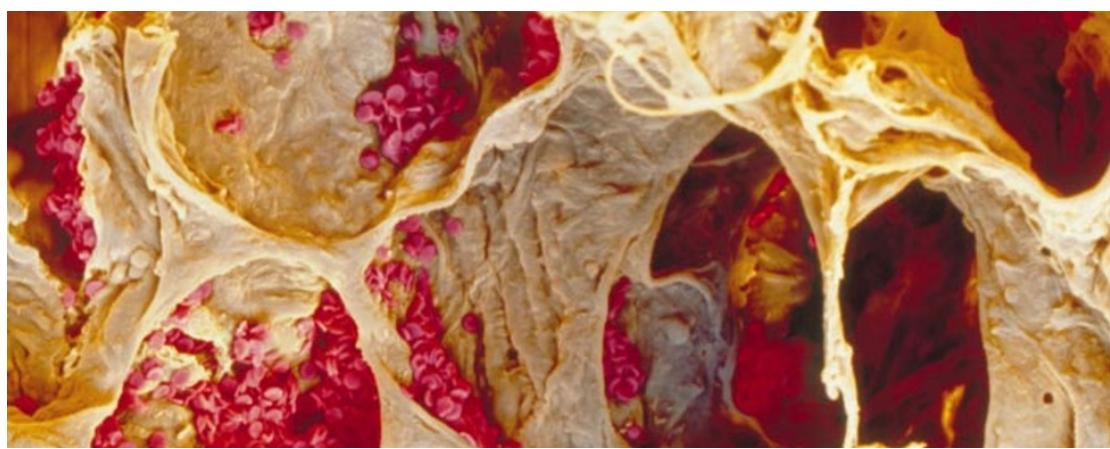

Many researchers say tobacco firms shouldn't sponsor research on topics such as lung cancer (pictured).

have agreed on a policy that is acceptable to the foundation, and the remainder have declined to accept the organization's grants.

Researchers at the UCSD Cancer Center also voted this month to disallow tobacco research money, but university officials have not yet acted on it. If they fail to do so by next month, David Burns, a physician who studies tobacco control at the centre, is set to lose a $\$ 500,000$ grant from the Legacy Foundation. Like UCSF's researchers, staff at the UCSD Cancer Center say that they do not actually receive any funding from tobacco firms.

The impasse has prompted the University of California's systemwide Academic Senate, which represents top academics at all nine of the university's campuses, to undertake to formulate a single, consistent policy. But this could take a year - during which time no University of California researcher will be eligible for a Legacy Foundation grant. Gayle Binion, a political scientist and chair of the senate, says that such an impasse would be "irrational", and hopes a compromise can be reached.

The Legacy Foundation is not the first to force universities to choose between its own funds and tobacco money. Two years ago, Britain's top cancer charities withheld funds from the University of Nottingham after it accepted $\mathfrak{£} 3.8$ million (US\$6 million) from British American Tobacco to set up a corporate ethics centre (see Nature Med. 7, 5;2001).

\section{Europe told to unite on spy satellites}

\section{Quirin Schiermeier, Munich}

The European Union (EU) needs a joint space-based military observation system to allow it to act for itself in global crises, says the union's research commissioner.

Speaking on 19 March at a conference on European security in Brussels, Philippe Busquin called for a research programme to aid in the development of such a system.

Satellites for military reconnaissance and intelligence gathering are being developed by at least four EU member states - but each is based on independent technologies.

"Security must be a key element of a European space policy," Busquin said.
“There should be no reason why Europe cannot develop the space assets that are fundamental to any credible security policy."

But according to some estimates, a common EU satellite-monitoring system would cost about $\mathrm{E} 8$ billion (US $\$ 8.5$ billion).

In January, the Greek EU presidency proposed a European agency similar to the US Defense Advanced Research Projects Agency (DARPA), which supports defence projects in many fields (see Nature 421, 465; 2003). The European Commission will this year ask representatives from member states, industry and research organizations to draft a defence-research agenda for the EU. 